\title{
Fly over the Clouds or Drive through the Crowd: A Cloud Adoption Framework in Action
}

\author{
Eman M. Ezzat \\ Informatics and Computer \\ Sciences \\ The British University in Egypt, \\ Cairo, Egypt
}

\author{
Doaa S. Elzanfaly \\ Informatics and Computer \\ Sciences \\ ICS Faculty- Helwan Univ. \& \\ The British Univ. in Egypt \\ Cairo, Egypt
}

\author{
Mostafa A. Mostafa \\ Computing and Information technology \\ Arab Academy for Science and \\ Technology \\ Cairo, Egypt
}

\begin{abstract}
Flying over the clouds or driving through the crowd, to work in an auto-managed and scalable environment or to get overwhelmed with the management as well as the development techniques and costly resources. That is a common problem facing most small to medium sized organizations. Cloud computing has been a breakthrough recently helping in the emergence of new resources, management, and services sharing between users and providers. With the consideration of the quality of services as a crucial factor for evaluating any service, the decision of adopting the new cloud techniques or remain in premise is one of the problems that faces the decision makers. The work proposed in this paper concentrates on surveying and studying the cloud among different professionals' perspectives and researches to be able to determine the most important and common aspects that affect the decision of cloud adoption. Furthermore, it considers in action the quality of services that are proposed to be the most effective while deciding. The factors determined are classified and used to set the infrastructure of building a full framework to facilitate the user's adoption decision. An evaluation model is proposed as well to measure the efficiency of the framework within real life.
\end{abstract}

\section{Keywords}

Cloud computing; Cloud adoption; quality of service; measurements factors.

\section{Introduction}

Flying over the clouds or driving through the crowd, that is the concern nowadays for most users. After the globalization has given the chance to small and medium enterprises to leverage ahead along with large ones; still the problem has always been the resources availability and limited capabilities. Cloud computing concept was exposed recently global wide offering the following capabilities: services and resources sharing, external information storing, full availability, autoscalability and most importantly pay-as-you-go or the services renting concept.

The concept of Cloud computing is not new; it has been introduced in 1969; the evolution paradigm began at the entrance of the new millennium 2000; allowing the users to work with only needed resources, services, and budget. With the introduction to the new concept (software as a service) people started to learn and interact with the cloud in many fields [1].
Although flying (Cloud usage) is much faster, more flexible and proved to be efficient enough to begin working, driving through the crowd (on-premise usage) is still considered as the safe choice to most of the users nowadays. The main reasons are: lacking the knowledge of the cloud concept, the working strategy compatibility issues, as whether adopting cloud technologies will be applicable to specific working environment or not, and finally, the ability of measuring the cloud adoption benefits, outcomes, compatibility factors and consequences, and functionality evaluation.

Previous Researches [2-9] basically concentrate on defining cloud computing, studying its architecture and capabilities without discovering if it is possible for a business field to use cloud technologies or not. Further they do not allow new users to define their problem and evaluate their decision based on specific influential factors. Outcomes measurements, security, management and other aspects are all considered as after cloud adoption factors for the users and professionals. The Provided quality of the services takes a huge part of the consideration and assessment.

This paper surveys and studies the cloud among different professionals' perspective and researches to be able to determine the most important and common aspects that affect the decision of cloud adoption. A full framework is proposed based on the factors studied as an infrastructure for supporting the users' decision. In addition, the measurements criteria and assessment methods of the framework are also presented to be used for application evaluation.

A preliminary version of the framework is proposed in [10]. However, after studying the concerns of applying the preliminary framework in real-life cases, further updates are proposed to consider more effective aspects. The quality assessment and framework components efficiency evaluation is a target. After studying different assessment techniques, strategies and criteria [11], [12] another room of updates is given for enhancement and ensuring the efficiency measurements of the framework components. Some factors, such as customizability and configurability, proved to be of great importance. Through this paper both factors are studied in more details. In addition, a model of measuring the influence of the configurability and customizability levels is proposed among the other evaluation criteria. 
This paper is organized as follows, after surveying professional users of the cloud technologies and studying the literature, a classification of cloud computing definitions has been introduced in the second section. Then, in the third section, different characteristics that affect the proposed framework are studied and further defined in terms of importance. Related work is discussed in the fourth section. A brief description of self-conducted survey is introduced in the fifth section. Then, based on the outcomes of the conducted survey, the proposed framework is explained in details in the sixth section. Afterwards, the quality of service as a concept is discussed. To be able to apply the framework and study its efficiency, the measurements criteria and assessment methods are proposed. Finally, the application of the framework in real life is concluded at the end of the paper with a conclusion and a future scope of the work.

\section{Cloud Definition}

As the technical concept is still in its evolutionary paradigm, there is not a standard definition for the term "cloud computing" yet. The concept is still mixed up between different definitions among multiple points of views. A lot of studies were developed to define cloud computing; we found it better to introduce them from two perspectives, the research groups' perspective and cloud professional users one. The NIST ${ }^{1}$, as a research institute, has defined the cloud computing as follows "Cloud computing is a model for enabling convenient, on-demand network access to a shared pool of configurable computing resources (e.g., networks, servers, storage, applications, and services) that can be rapidly provisioned and released with minimal management effort or service provider interaction." [9]. While Forrester research group has defined it in [13] as "A standardized IT capability (services, software, or infrastructure) delivered via the Internet in a pay per- use and self-service way". IBM group has defined the cloud to be "Cloud computing is a model for delivering information services that provide flexible use of virtual services, massive scalability, and management services" [14]. Another group of researches in [15] gave the following definition "A cloud computing is the style of computing where massively scaled IT related capabilities are provided as a service across the internet to multiple external customers and are billed by consumption". By studying these definitions, it has been found that the main concern over cloud computing is sharing different resources over the internet with the focus on payment, scalability and different provided capabilities.

From the professional perspectives, acquired from the conducted survey, different points of views of cloud computing users have been collected among different business fields. Table-1 lists some of the surveyed definitions. With the aid of these professionals' definitions, a new dimension has been engaged to the cloud computing definition which is the quality of such services. A project manager at IBM UK defined it as "Computing in which services and storage are shared over the internet". A software engineer at ITworx Egypt gave the following definition: "Cloud Computing is all about providing IT resources as a service which includes software, hardware, and platform. Most importantly these resources should be shared across clients and scalable to suite live demand.

\footnotetext{
${ }^{1}$ NIST : National Institute of Standards and Technology
}

Table 1. Professionals' Cloud Computing Definition

\begin{tabular}{|c|c|c|c|}
\hline Profession & $\begin{array}{l}\text { Work } \\
\text { Field }\end{array}$ & Cloud field & Definition \\
\hline $\begin{array}{c}\text { Project } \\
\text { manager }\end{array}$ & Business & Storage & $\begin{array}{l}\text { Computing in which services } \\
\text { and storage are shared over } \\
\text { the internet (the cloud) }\end{array}$ \\
\hline $\begin{array}{l}\text { Research } \\
\text { Student }\end{array}$ & Medical & Mail servers & $\begin{array}{l}\text { Cloud computing is the } \\
\text { ability to remotely access } \\
\text { computer servers to perform } \\
\text { high-computation actions and } \\
\text { processes. This gives users } \\
\text { the opportunity to use } \\
\text { programs and/or memory } \\
\text { banks to perform processes } \\
\text { they may not be able to } \\
\text { perform on their on-premise } \\
\text { computers. }\end{array}$ \\
\hline $\begin{array}{l}\text { Research } \\
\text { Engineer } \\
\text { (Cloud } \\
\text { Technolog- } \\
\quad \text { ies) }\end{array}$ & Business & $\begin{array}{l}\text { Education, } \\
\text { Mail, IM }\end{array}$ & $\begin{array}{l}\text { Cloud Computing is all about } \\
\text { providing IT resources as a } \\
\text { service which includes } \\
\text { software, hardware, and } \\
\text { platform. Most importantly } \\
\text { these resources should be } \\
\text { shared across clients and } \\
\text { scalable to suite live demand. } \\
\text { Keywords of cloud } \\
\text { computing is multi-tenancy, } \\
\text { scalability, and availability. }\end{array}$ \\
\hline $\begin{array}{c}\text { IT } \\
\text { consultant }\end{array}$ & $\begin{array}{c}\text { Telecommu } \\
\text { nications }\end{array}$ & $\begin{array}{l}\text { Mails } \\
\text { servers, } \\
\text { Education }\end{array}$ & $\begin{array}{l}\text { It is the ability to host your } \\
\text { application in an } \\
\text { environment that can scale up } \\
\text { or down as needed. }\end{array}$ \\
\hline $\begin{array}{l}\text { Software } \\
\text { Engineer }\end{array}$ & $\begin{array}{l}\text { Software } \\
\text { industry }\end{array}$ & $\begin{array}{c}\text { Social } \\
\text { applications }\end{array}$ & $\begin{array}{l}\text { Cloud computing means that } \\
\text { computing resources, data } \\
\text { storage etc. are accessible via } \\
\text { the internet on-demand. }\end{array}$ \\
\hline $\begin{array}{l}\text { Application } \\
\text { Specialist }\end{array}$ & Business & $\begin{array}{l}\text { Oracle, RPG } \\
\text { (IBM) }\end{array}$ & $\begin{array}{l}\text { Top used soft- } \\
\text { wares/applications in the } \\
\text { market. }\end{array}$ \\
\hline $\begin{array}{c}\text { CRM } \\
\text { Consultant }\end{array}$ & Consulting & $\begin{array}{c}\text { SIEBEL } \\
\text { CRM } \\
\text { OnDemand, } \\
\text { Salesforce, } \\
\text { Google Docs, } \\
\text { Sugar CRM, } \\
\text { Vtiger CRM }\end{array}$ & $\begin{array}{c}\text { Software products which } \\
\text { exposed as Service for end } \\
\text { users to be used as software. } \\
\text { No hardware or infrastructure } \\
\text { maintenance or buying } \\
\text { software. }\end{array}$ \\
\hline $\begin{array}{l}\text { Medical } \\
\text { Informatics } \\
\text { PhD } \\
\text { Candidate }\end{array}$ & Education & $\begin{array}{c}\text { Clinical } \\
\text { Informatics, } \\
\text { Simulations } \\
\text { and } \\
\text { Predictions, } \\
\text { Systems } \\
\text { Science, } \\
\text { EMR } \\
\text { Analysis }\end{array}$ & $\begin{array}{l}\text { Cloud computing is a service } \\
\text { of easily usable and } \\
\text { accessible virtualized } \\
\text { resources, such as } \\
\text { infrastructure (hardware), } \\
\text { platforms, and software. } \\
\text { These resources can be } \\
\text { dynamically allocated to } \\
\text { meet changing workload } \\
\text { requirements. The utility of } \\
\text { cloud computing allows } \\
\text { informaticists to explore } \\
\text { translational research. }\end{array}$ \\
\hline
\end{tabular}

Keywords of cloud computing is multi-tenancy, scalability, and availability". Concluding these definitions, cloud computing can be said to be a generic defined technology in its emergence state; it's a way of virtual working environment customizable upon users' needs, while paying only for the used services, resources and information are shared remotely over the web with respect to quality of rented services.

\section{Cloud Characteristics}

The availability of many capabilities and characteristics of cloud services has proved being an efficient solution for deciding moving over the cloud. Facilitating the development 
of many tasks, enhancing and simplifying the working environment in different fields are considered as a solution for most of experienced challenges and bottlenecks; such as management overhead, un-determined scalability problems, costly resources, and limited capabilities of developers. After the cloud has been researched [14], [15], [16], [17]; some concluded properties are considered as common and are taken as factors when developing the infrastructure of the proposed framework. The following list demonstrates these properties as collected among different fields and grouped according to their importance and commonality.

\author{
On-demand/ scalability \\ Lower cost/ pay-as-you-go \\ Multi-tenancy \\ SLA-driven \\ Elasticity \\ Flexibility/ease of use \\ Virtualization \\ Configurability/ customization \\ Broad network access \\ External Data Storage \\ Application migration \\ Managed \\ Abstraction/Transparency
}

After the adoption of cloud computing in multiple fields and as a result of its capabilities, users may gain benefits in many ways; around cost savings because of the pay-as-you-go concept, management overhead reduction, high-level computing, auto-scalability depending on the service usage and work load solving the problem of large processing with no use, resources availability, data storage with location independability, time-sharing, automatic re-configurability, less complications and flexible services, and different platforms dependability for easily accessing and 24/7 access. Although the cloud computing, among multiple users, has been a good solution; the problem standing in the middle lies in some unsolved challenges that can be classified into cultural, security and performance ones. For the cultural challenges, people resistance to change is the main one as usually people turn to be afraid of the changing idea. Security issues are concerned with the privacy of information shared and stored over unknown locations, plus the legality issues including the governmental policies of each region. For the performance challenges, the common exposed one is the performance and service delivery management, where, the provider is still the one who is in full charge and can manage the service even after approving the service level agreements. Some users consider this as a benefit and a drawback at the same time.

\section{Related Work}

Most studies in the literature conducted by institutes, researchers and surveys, are all concentrating on the concept of cloud computing as a technology [6], [8], [9], [18], [20], [21]. They are studying the cloud as a definition, architecture and common usability; while only few are mentioning the business perspective [5], [7], [18], [19], [22], [21] in terms of outcomes not in terms of the compatibility of the cloud to business. IBM research group has discussed a framework for cloud adoption in [19]. They started by defining a road map to adopt cloud service technically. Afterwards, in [18], they discussed their framework for cloud adoption; by defining different cloud services types and classifying them into service layer without discussing the effect of each layer on the adoption decision. KPMG institute has a survey for defining the usage of cloud within the business field, but from the perspective of knowing how cloud has proved being effective to the managers and the difference between cloud types [23]. The National Institute of Standards and Technology (NIST) in [22], has also studied the cloud in a technical and architectural perspective to identify a secured usage of the cloud without mentioning the compatibility part of the cloud and business fields. However, they proposed a valuation technique for estimating the cloud computing benefits. A framework of two main steps is discussed and applied in a sort of comparative model that compares between cloud and conventional solutions in a qualitative model. The first step concentrates on the business perspective. A business case was proposed to be developed including different aspects of the organization; but in terms of estimation, it was all proposed based on qualitative factors that were not even mentioned as core ones. The second step focuses on the cost analysis based on the factors deduced at the first step and then start deciding if it is feasible and compatible with the organization or not. The NIST framework in [18] is the most relevant to our proposed study and has helped as a foundation to the suggested framework.

\section{Conducted Work}

In order to apply the practical perspective and know what exactly affects the decision of adopting cloud techniques; different individuals and professional users knowledgeable with cloud computing concept were survived. The main target of the survey is to gather information about adopting cloud in multiple working fields to be able to derive the common and most important factors and aspects that support the adoption decision.

The survey covers multiple aspects classified as follows; first, exploring the professional business field to be able to determine how cloud affects business in different fields. Second, identifying the basic knowledge of cloud, asking the users to define the cloud from their own point of view to be able to know how exactly people are knowledgeable with the cloud concept and their culture. Third, discussing the usage of cloud and whether they get benefit from using the cloud or not. Afterwards the survey covers the provider to be able to know who provides diverse cloud techniques and which is considered better by providing the service and to which extent the user trust and chose them. Finally each user is requested to rank different factors that may be persuasive while deciding to adopt cloud services and to add any other important factors that may affect their decision.

After analyzing the survey precisely, some main points were clarified that have proved being crucial to support the adoption decision. Figure 1 shows the percentage of the importance of each factor based on professional prioritization and concludes the main ones that are used as an infrastructure layer in the proposed framework. It is clear that the most important factor while deciding to adopt cloud services was found to be the cost for most of the fields and among all of the professions, then comes the services and functionalities offered by the cloud application/service itself.
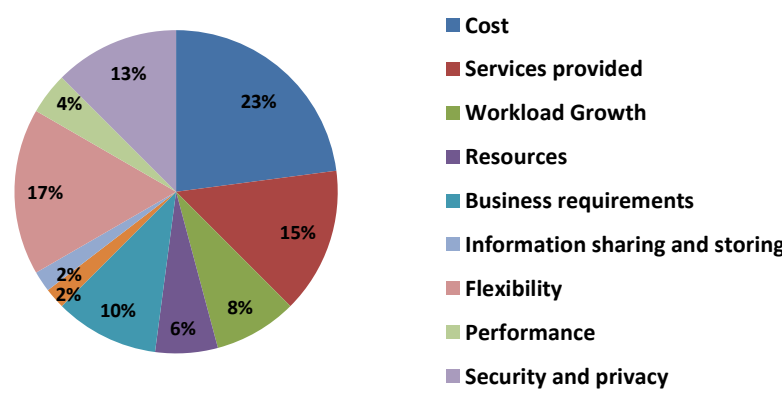

Figure 1 - Statistical study- factors Percentage of Importance 


\section{Cloud adoption framework}

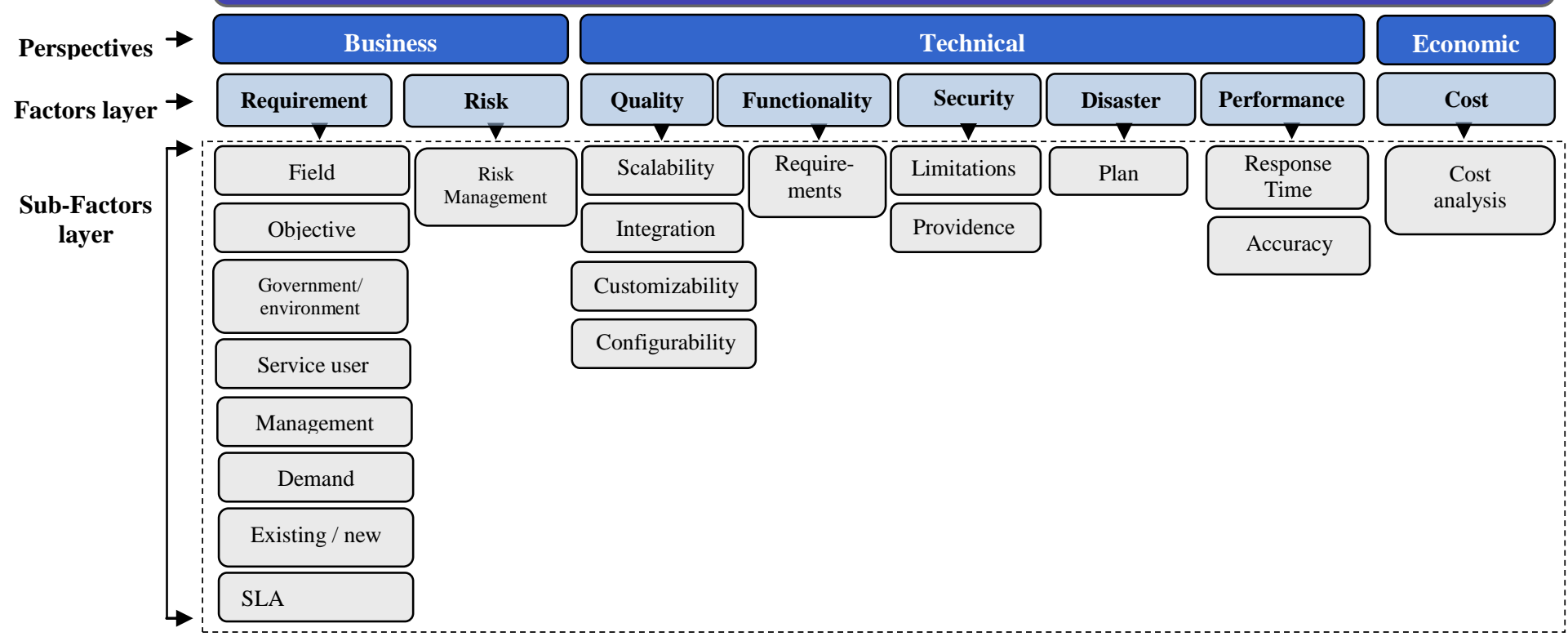

Figure 2 - Proposed Cloud Adoption Framewrok

\section{Cloud Adoption framework}

The main target of the proposed framework is to help users in cloud computing adoption decision making depending on their own business case. Based on different studies from the literature such as perspective [5], [7], [18], [19], [22], [23] and the conducted survey, it was clear that business requirements are not of less importance than the technical needs to make the cloud adaption decide. The working environment, covering legal and governmental issues, is also an effective factor to consider. These factors were considered when proposing the layers of the proposed framework. The key element of the framework is to integrate the business and technical perspectives with respect to the economical aspect as well.

As shown in Figure 2, the proposed framework is composed of three main layers; the first layer is the integration between business, technical and economical perspectives as all hold the same level of importance. In the second layer, come the basic factors that are considered under each perspective. The final layer is a further decomposition of sub-factors within each basic factor for assessment and evaluation. Each layer along with its factors is discussed in the following subsections.

\subsection{Business Perspective Layer}

Any new working strategy, project or even upgrading idea should be dealt as a full new business pitch; that needs a full professional case to cover and identify all the elements included to be accomplished. Any business case covers the possible elements that can affect the business needs. Business perspective (or business scenario) is studied in terms of two main factors: business requirements description and risk management.

\subsubsection{Business Requirements}

The business case describes the organization as a whole to determine the basic use, business needs, analyze the resources and requirements in terms of business type description and application usage; it is so called as business case definition and it includes the following:

- $\quad$ Business field "e.g. educational, banking, etc."

- Location: Government, environment

- Target user: Service receiver/user

- Demand: prediction of the usage/ demand over the service

- Existing/new: type of service "e.g. upgrade of an existing one or a full new technology"

- Service level agreement

- Barriers: constraints that may affect the business.

Business cases contents differs from one to another. Multiple of elements may be included. In this case only the ones that may affect the choice and decision of cloud service adoption are included. The question now is how to evaluate these inputs to be able to take the right decision. Multiple evaluation and assessment methods and criteria are studied [24], [25]. The most relevant ones from the authors' point of views are studied below.

One of the business cases evaluation criteria studied in [24] used some sort of scoring system specifically for IT business case studies. Ten measuring criteria were introduced specifically for business cases. They proposed a scoring system that ranges from 0 to 10 for each criterion. Getting the output of percentage score as well as a sufficient profile of purpose that can be used to map with strategic purposes. Other Corporate strategies have their own Evaluation criteria form as the one referred [25]. They proposed a clear theoretical evaluation form with two measurements choices either meeting or failing to meet the requirements; then the scoring is calculated from 1 to 10 with the categories of fully meeting the requirements ( 8 to 10 ), generally meets the requirements ( 5 to 7 ) or doesn't meet them (1 to 4). 


\subsubsection{Risk Management}

Risk management factor is identified as a crucial and influential aspect for multiple of users and professionals. Risk management is a full study in terms of any project that has its methods and considerations. It covers the risks that may face the service or the overall project and how it can be managed. The ones that will be considered in the proposed framework are listed below in terms of:

Weather it is provided or not,

- the level of managing risk,

- extra techniques used, ease of use, and

- clarity and considerations of plans

\subsection{Technical Perspective layer}

This layer concentrates on the technical application itself. Through this layer the technical aspect is broken down and analyzed, in terms of quality of the service needed from different aspects plus the provided functionalities covering the functional requirements, in addition to security and disaster recovery, and then grouping the performance factors in a different sub-layer based on their importance as follows:

\subsubsection{Quality of Service}

Quality of service is not that different when Cloud or onpremise services are mentioned. It is all about measuring and assuring the quality of the service itself based on some defined parameters. Qualified service means: the desired outcome is met, the performance level is efficient, and the needed function is performed in an acceptable manner. However, there are some other factors, such as scalability and integration that differ in ways of measurement and consideration if they are on the cloud or on-premise. The factors considered here under the Quality of Service layer are thought to be the most persuasive and essential to analyze and measure while working on the cloud. Moreover, two other factors are considered that were not considered in most of the previous studies but proved to be essential to evaluate; customizability and configurability.

Scalability: one of the main benefits of the cloud services is the auto-scalability property which is very influential to any user; that is why this factor must be of high quality and considered as a critical measurement. A proposed method to use when determining the level of scalability is the Quantitative Scalability Evaluation Method (QSEM) proposed in [26] that is concluding the scalability of a system by seven steps in case of an existing system.

- Integration: based on the type of service needed as whether it is compatible to integrate with another one or not.

- Customizability: The user must define the need of customization as if it is an essential one and with the level of its importance it will determine the level of need for cloud.

- Configurability: The need of user-configurable and flexible service is another factor that is considered in the suggested framework that would determine precisely the compatible service type.

\subsubsection{Functional Requirements}

This part concerns with a common full descriptive definition for the functions needed within the service. This would help the user be more structured to determine the functionalities that should be developed in a manner that will be later used as a checklist to determine their availability to the proposed solution.

\subsubsection{Security}

Based on the limitations faced by different users and professionals deduced from the conducted study, cloud services security is still a bottle neck in the adoption decision. Security factor was added in respect to the following; the required security level based on the business needs, the business field, as it affects the required level. As proved by a senior associate technical consultant at a well known software house in Egypt, ITworx, specialized in cloud services and a partner trainer for cloud services with a Microsoft,

"An educational application has been developed and offered over the cloud to one of our customers, educational public sector at an international country; when we tended to talk about the cloud privacy the customer chose the lowest security level as they claimed the data stored are already published and used in public so no need to further complicated security issues are considered"

Moreover, based on the required security level the type of the cloud services is defined. A private, public or hybrid type is defined based on the confidentiality and security level required. In some cases, the cost is also affected by this level identification as some vendors offer the public services in less cost than the private ones.

\subsubsection{Disaster Recovery}

Disaster recovery is one of the main factors that should be added to build the trustfulness between the provider and the user. Based on many professionals needs and real-life case studies [27],[28]. Disaster recovery providence and availability has a persuasive effect for building a kind of loyalty and influence towards the cloud services. The factors that are considered in our framework are the availability and the plan for recovery; which is the backup plan in case of any crashes, malfunctions, data loss, etc.

In aSalesForce, the pioneer in CRM cloud services providing, are identified this factor as one of the major seven standards for any cloud service delivery [27].

\subsubsection{Performance}

The performance factor targets the processing and output of the service in terms of performance measurement. Different methods were proposed in the literature review for measuring the performance of cloud applications. Most of these studied performance measurements techniques were all concerned with defining some metrics for assessing the performance of any system or service [33-36]. The metrics considered in this work focuses on the common surveyed users' point of view; that were found to be both the response time and the output accuracy.

It is very important to determine the needed cloud service performance level by exactly knowing the target response time plus considering the output accuracy level. 
The response time differs whether it is just in time or real time, .etc. This must be measured to be able to know whether the needed level can be found in any previously known cloud service or it is not recommended and better remain on premise.

Furthermore the output accuracy has been found to be a very important aspect when taking any decision affecting the adoption. In case of many applications the highest prioritized target is accurate output for many users; while in some cases other criteria make a difference than the output itself such as high processing and so forth.

\subsection{Economical Perspective Layer}

This final perspective to consider in the proposed framework concentrates over quantitative aspect. The economical aspect includes a precise cost analysis for the needed application/service to define whether if it is better to adopt the cloud or remain with on-premise capabilities. The cost benefit analysis has been proposed in many ways and multiple of techniques had been studied such as the ones in [5], [29], [30], [31].

\section{Measurements and evaluation}

In this section, an assessment technique for the adoption framework factors is proposed to be able to evaluate its applicability in real life. A numeric measurement criterion is proposed for each factor with respect to its type. Equilibrium is being made by the end in terms of equivalent measurement to get the full output and decide whether to adopt or not.

\subsection{Business Layer}

As mentioned above there are multiple of business cases forms and contents, but if a generic one is considered as proposed within the framework and one of the main business case evaluation criteria is chosen as in [25] scoring measurement of meeting the desired criteria or failing to meet it is considered in this case, the meet criteria will be equals to 1 and fails will be equivalent to 0 . Risk management part will be calculated by the risk exposure in [31]; a weight of $>1=1$ and $<1=0$.

\subsection{Tehcnical Layer}

\subsubsection{Scalability}

In terms of scalability it has been proposed at this stage of the framework to measure it in terms of predicted or auto needed as not known by the user. Where predicted is 0 and auto scalability required is 1 .

\subsubsection{Customizability/ Configurability/ Integration}

For customizability, up to our knowledge, there are not any specific techniques for assessing and measuring customizability. After studying the importance of the factor and how it can affect the decision of users in real-life cases [28], a full measurement tool is being proposed where some criteria are considered and each one of them is given a specific numeric value ranging from intervals of $[-1,1]$. Configurability and integration are both measured with the same measurements as the customizability. Table 2 shows each of the measurements criteria considered and its equivalent numeric value.
Table 2 Customizability Measurements Criteria and the Numerical Equivalence

\begin{tabular}{|c|c|c|}
\hline Measurement & Criteria & $\begin{array}{c}\text { Numeric } \\
\text { value }\end{array}$ \\
\hline \multirow{4}{*}{$\begin{array}{l}\text { Customizability level } \\
\text { (provided/ needed) }\end{array}$} & None & -1 \\
\hline & Low & 0 \\
\hline & Average & 1 \\
\hline & Influential & 1 \\
\hline \multirow{3}{*}{ Ease of use (easiness) } & Low & -1 \\
\hline & Average & 0 \\
\hline & Easy & 1 \\
\hline \multirow{2}{*}{ Cost } & None & 1 \\
\hline & Cost & 0 \\
\hline \multirow{3}{*}{ Flexibility, readiness } & Low & -1 \\
\hline & Average & 0 \\
\hline & Influential & 1 \\
\hline \multirow{2}{*}{$\begin{array}{l}\text { Extra Technologies needed } \\
\text { to customize application }\end{array}$} & None & 1 \\
\hline & Active & -1 \\
\hline
\end{tabular}

\subsubsection{Performance/ Security}

The main focus in the study is not related to calculating the performance or the security output. Only the required level of both of them will be weighted as:

High Performance/ Security level $=1$

Low Performance/ Security Level $=-1$

Average Performance/ Security Level $=0$

\subsubsection{Accuracy}

Accuracy level is measured in terms of required output accuracy. With the respect to the expected output data from the providers as pre-defined and the field of business as well. Table 3 lists the measurements and their numerical equivalence.

The final calculations are performed as a submission to all of the measurement numerical values. Scoring the output percentage of the considered aspects measuring some criteria e.g. high, low, average, influential, ...etc. The scoring will give an overview image of the level of cloud adoption efficiency in an approximate mathematical number.

Efficiency Value $=$ Business case + Risk exposure + QOS value + Security level + Performance level

$$
\mathrm{EV}=\mathrm{BC}+\mathrm{RE}+\mathrm{QOSV}+\mathrm{SL}+\mathrm{PL}
$$

Table 3 Accuracy Measurements Criteria and the Numerical Equivalence

\begin{tabular}{|c|c|c|}
\hline Measurement & Criteria & Numeric value \\
\hline \multirow{2}{*}{$\begin{array}{c}\text { Accuracy Level } \\
\text { provided }\end{array}$} & Low & -1 \\
\cline { 2 - 3 } & Average & 0 \\
\cline { 2 - 3 } & Accurate & 1 \\
\hline
\end{tabular}




\section{Case Study}

With the aim of evaluating the efficiency of the framework, a real life case study is used to apply the measurement technique proposed above.

The NaviSite incorporate [28] has been working in the hosting, managing and maintaining for customers Oracle applications since 1997. It had passed through different advancement stages of hosting providence and customer satisfaction development techniques. Their main target was using the advanced technologies in getting best results and satisfying the customer's needs with a room of high flexibility and performance.

The NaviSite case study is used to evaluate the proposed adoption framework. A full description of each of the framework's element for business and technical perspective are summarized in Table 4 and Table 5 respectively.

Table 4 Case Study Parameters for Business Layer

\begin{tabular}{|c|c|c|}
\hline Measurement & Criteria & value \\
\hline \multirow{7}{*}{ Business Case } & Field & $\begin{array}{l}\text { Technology, complex hosting } \\
\text { and managing applications } \\
\text { Objective: hosting, managing, } \\
\text { and maintaining customers } \\
\text { Oracle application }\end{array}$ \\
\hline & Government & USA, Global \\
\hline & Service user & Oracle application users \\
\hline & Existing/ New & existing advancement \\
\hline & SLA & provided and signed \\
\hline & Management & Both (Navisite, customers side) \\
\hline & Demand & $\begin{array}{l}\text { Unpredicted, varies in high and } \\
\text { low demand }\end{array}$ \\
\hline $\begin{array}{c}\text { Risk } \\
\text { management }\end{array}$ & Level & Unspecified \\
\hline
\end{tabular}

As the second factor of the technical layer is based on the service needed Functionalities, services and functionalities as required by NaviSite and even more are listed and provided by the virtual cloud application. It provides computing, networking, storage, and virtualization in a cohesive system managed as a single entity, allow high capacity of storage to manage the auto scalability, provide single pair of Cisco UCS 6100 fabric interconnects over $10 \mathrm{~GB}$ Ethernet to a Cisco Nexus 7000 series switch over Fiber Channel to IBM XIB storage. These services provided cover all of the needs to the change required by NaviSite. In which the requirements were basically a needed platform with high performance, high availability and security in a multitenant environment with flexible options.

While having most of the factors as influential and calculating the output to get EV >= 7 which is considered as above average and even having the high cost reduction as mentioned by the company senior vice president of enterprise and application services for NaviSite [28].
Table 5 Case Study Parameters for Technical Layer

\begin{tabular}{|c|c|c|}
\hline Measurement & Criteria & value \\
\hline Scalability & Predicted Level & $\begin{array}{c}\text { un- } \\
\text { known, } \\
\text { Auto }=1\end{array}$ \\
\hline \multirow{5}{*}{ Customizability } & Provided "Average" & 1 \\
\hline & Cost-None & 1 \\
\hline & Ease of use- Easy & 1 \\
\hline & Flexibility-influential & 1 \\
\hline & Extra technologies- None & 1 \\
\hline \multirow{6}{*}{ Configurability } & Provided "Average" & 1 \\
\hline & Provided "Average" & 1 \\
\hline & Ease of use- Easy & 1 \\
\hline & Cost-None & 1 \\
\hline & Flexibility-influential & 1 \\
\hline & Extra technologies- None & 1 \\
\hline Accuracy Level provided & Accurate & 1 \\
\hline Performance level & High & 1 \\
\hline Security level & Average & 0 \\
\hline \multicolumn{2}{|c|}{ Total } & 14 \\
\hline
\end{tabular}

Then the weight will be doubled and having the full business case of meeting factors so by scoring using the NDR [22] scoring schema so the fully meeting requirements will be categorized between intervals of $[8,10]$ and by meeting the whole requirements it would be 10 , equalized in our framework to be $=1$. By using the equation (1) for total measurements, the weight is nearly 10 , which means it worth the chance and the adoption.

\section{Conclusion}

This paper proposes a cloud adoption framework that integrates between business, technical and quality of cloud service aspects in a unified structured with an evaluation measurement methodology to ensure the compatibility of the service with specific business case; helping the users taking the decision of either adopting the cloud or remaining onpremise. The outcome of applying the framework, along with its measurements, on a real life case study was in alignment with actual the adoption decision. A future scope of this paper is to cover the security issue within the framework not just from the conceptual perspective but rather to focus on a full security infrastructure consideration for the service to adopt. Cultural gap and change resistance will also be a focus in the future scope to be able to be more convincing and bridge the gap between the providers and users.

\section{References}

[1] L. Wang, G. Laszewski, M. Kunze, and J. Tao, "Cloud computing: a perspective study", New Generation Computing, 2010, vol. 28, no. 2, pp. 137-146.

[2] B. P. Rimal, E. Choi and I. Lumb., A Taxonomy, Survey, and Issues of Cloud Computing Ecosystems, 2010, In: N. Antonopoulos and L. Gillam Cloud Computing: 
Principles, Systems and Applications, Computer Communications and Networks. London: SpringerVerlag. pp. 21-46.

[3] N. Khan, A. Noraziah, M. M. Deris and E. I. Ismail, CLOUD COMPUTING: Comparison of Various Features. 2011, In: E. Ariwa and E. El-Qawasmeh DEIS 2011, CCIS 194. Berlin Heidelberg: Springer-Verlag. pp. 243-254.

[4] M. Armbrust, A. Fox, R. Griffith, A. D. Joseph et al, "A View of Cloud Computing", Communications of the ACM, 2010, vol. 53, no. 4, pp50-58.

[5] S. R. Marston, Z. Li, S. Bandyopadhya, J. Zhang et al., "Cloud computing - The business perspective", Journal of Decision Support Systems, 2011, Elsevier, vol. 52, no. 1, pp. 176-189.

[6] N. Sainath, S. Muralikrishna and P.V.S. Srinivas, "A Framework of Cloud Computing in the Real World", Research India Publications, 2010, vol.3, pp 175-190.

[7] R. Subramanian. 2010. Cloud Computing an Enterprise Perspective, Infosys Technologies, India.

[8] J. Hagel and J. Brown. 2010. Cloud Computing - Storms on the Horizon, Tech. Report, Deloitte Center for the Edge.

[9] P. Mell and T. Grance. 2009. Effectively and Securely Using the Cloud Computing Paradigm, NIST, Information Technology Laboratory.

[10] D.El Zanfaly, E. M. Ezzat and M.M. Kouta. 2011. Fly Over The Clouds or Drive Through The Crowds: Cloud adoption framework. In the Proceeding of the CTIT' 2011, UAE, Dubai.

[11] D. Armstrong and K. Djemame. 2009. Towards Quality of Service in the Cloud. White Paper, School of Computing, University of Leeds, UK.

[12] W. Pauley, "Cloud Provider Transparency: An Empirical Evaluation", IEEE Security and Privacy, 2010, vol. 8, no. 6, pp. 32-39.

[13] J. Staten, Is Cloud computing Rwady for the Enterprise, tech. report, Forrester Research,2008

[14] D. Sullivan. Changing the Way We Deliver Services with Cloud Computing. 2010, In: Don Jones The definitive guide to guide to cloud computing, vol. 1Ed. San Francisco, Realtime publishers IBM..

[15] N. Sainath, S. Muralikrishna and P.V.S. Srinivas, "A Framework of Cloud Computing in the Real World", Research India Publications, 2010, vol.3, pp 175-190.

[16] C. Gong, J. Liu, Q. Zhang, H. Chen et al. 2010. The Characteristics of Cloud Computing. In the 39th ICPPW-2010, San Diago, California, USA.

[17] M. A. Vouk, "Cloud Computing - Issues, Research and Implementations", Journal of Computing and Information Technology, 2008, vol. 16, no.4, pp. 235246.

[18] IBM research team. 2010. Defining a framework for cloud adoption. White Paper, IBM Global Technology Services.

[19] Keene, I. Poddar, J. Nicke and U. Budnik. 2009. Cloud Quick Start: A Roadmap For Adopting Cloud Computing. White paper. IBM.

[20] Information security briefing. 2010. Center of the Protection of the National Infrastructure, USA, Avaialble:http://www.cpni.gov.uk/Documents/Publicatio ns/2010/2010007-ISB_cloud_computing.pdf
[21] A. Goyal and S.Dadizadeh. 2009. A Survey on Cloud Computing, Tech Report, University of British Columbia, Vancouver, Canada.

[22] M. Klems, J. Nimis, and S. Tai. "Do Clouds Compute? A Framework for Estimating the Value of Cloud Computing", Lecture Notes in Business Information Procrssing, 2008, vol.22, pp. 110-123.

[23] M. Chung and J. Hermans, From Hype to Future. KPMG's 2010 Cloud Computing Survey. KPMG, 2010.

[24] Colin Beveridge. 2002. Aligning IT with Business Strategy", National Computer Center, UK, Avaialble FTP:http://www.ictknowledgebase.org.uk/fileadmin/ICT/ pdf/NCC/Align_IT_with_strategy.pdf

[25] Business Case Evaluation Forme. 2009. Nuclear Aecommissioning Authority, UK, Avaialble FTP:

http://www.nda.gov.uk/documents/upload/EGG08-F01Business-case-evaluation-form-Rev2.doc

[26] L. G. Williams and C. U. Smith. 2005. QSEMSM: Quantitative Scalability Evaluation Method. In the Proceedings of the Computer Measurement Group, Orlando.

[27] BMC Software, Inc. The Seven Standards of Cloud Computing Service Delivery. 2009. White Paper, SalesForce.com

[28] CISCO corp. 2010. Hosting service provider manages Oracle Applications in the cloud. Case Study, Available FTP:http://www.cisco.com/en/US/solutions/collateral/ns 340/ns517/ns224/ns955/ns967/NaviSite_cStudy.pdf

[29] J. G. Koomey, K. G. Brill, P. Turner, J. Stanley et al. 2007. A Simple Model for Determining True Total Cost of Ownership for Data Centers. White Paper, Uptime Institute.

[30] M. Klems. 2008, July 1. Cloud TCO Part 2. Online, Available:http://markusklems.wordpress.com/2008/07/01 /cloud-tco-part-2/.

[31] H. L. Truong and S. Dustdar, "Composable Cost Estimation and Monitoring for Computational Applications in Cloud Computing Environments", Procedia Computer Sciense, 2010, vol. 1, no. 1, pp 2175-2184..

[32] Hughes, B. and Cotterell, M., 2006. Software Project Management", 4th Edition, McGraw Hill.

[33] R. Iosup, S. Ostermann, N. Yigitbasi, R. Prodan et al. 2008. An early performance analysis of cloud computing services for scientific computing, Technical Reprot, TU Delft.

[34] L. G. Williams and C. U. Smith. 2002. PASASM: A Method for the Performance Assessment of Software Architectures. In Proceedings of the Workshop on Software and Performance (WOSP2002), Rome, Italy.

[35] K. Xiong and H. Perros. 2009. Service Performance and Analysis in Cloud Computing. Congress on Services - I IEEE Press.

[36] A. Waters. 2010, August 14. 4 tools for assessing cloud performance. Online Available: www.readwriteweb.com/cloud/2010/08/tools-forassessing-cloud-perf.php. 